\title{
Numerical Modeling of the Effect of Fine Water Mist on the Small Scale Flame Spreading Over Solid Combustibles
}

\author{
A.I. KARPOV ${ }^{1}$, V. NOVOZHILOV ${ }^{2}$, V.K. BULGAKOV ${ }^{3}$, and A.A. GALAT ${ }^{1}$ \\ ${ }^{1}$ Department of Computer Science \\ Komsomolsk-on-Amur State University of Technology \\ Komsomolsk-on-Amur 681013, Russia \\ ${ }^{2}$ Fire Safety Engineering Research and Technology Centre, \\ University of Ulster \\ Newtownabbey BT37 0QB, UK \\ ${ }^{3}$ Khabarovsk State University of Technology \\ Khabarovsk 680035, Russia
}

\begin{abstract}
A CFD model has been developed to predict the behavior of the flame spread over solid fuels in water mist environment. A coupled analysis involving gas phase and solid fuel is considered using unsteady two-dimensional conservation equations describing the selfsustained flame propagation. Due to the analysis is focused on the mechanism of flame suppression at the flame leading edge, which is explicitly exposed to the mist, finite-rate chemical reaction is taken into account. The equations for water mist and vapor mass fractions are added to the basic flame spread statement, which includes corresponding term describing energy consumption due to water evaporation. Horizontal flame spread over thick fuel beds of polymeric material (PMMA) under water mist suppression has been investigated. The results have shown that self-sustained energy balance in the heat release zone in the flame is highly sensitive to the external energy loss, which in this case is due to water droplet evaporation. Thus, flame struggles against the presence of water mist on the flame leading edge and either continues to propagate with almost the same velocity (as of without water mist), or complete extinction occurs. The extinguishing characteristics of fine water mist with the droplet diameter of the order of 30 microns are investigated. A critical concentrations of initial water mist mass fraction required for extinguishment have been achieved for the various conditions of flame spread phenomenon.
\end{abstract}

KEYWORDS: flame spread, CFD modeling, water mist, fire suppression

\section{NOMENCLATURE}

\begin{tabular}{|c|c|c|}
\hline specific heat & $v_{s}$ & pyrolysis rate \\
\hline diffusion coefficient & $W$ & chemical reaction's rate \\
\hline droplet diameter & $x$ & tangential coordinate \\
\hline activation energy & $Y$ & mass fraction \\
\hline gravity acceleration & $y$ & normal coordinate \\
\hline preexponential factor & Greek & \\
\hline evaporation constant & $\lambda$ & thermal conductivity \\
\hline thickness of solid fuel & $\mu$ & viscosity \\
\hline heat of evaporation & $v$ & stoichiometric coefficien \\
\hline
\end{tabular}




\begin{tabular}{|c|c|c|c|}
\hline$m_{w}$ & rate of water evaporation & $\rho$ & density \\
\hline$p$ & pressure & \multicolumn{2}{|c|}{ Subscripts } \\
\hline$Q$ & heat of reaction & $a$ & ambient \\
\hline$R$ & specific gas constant & $F$ & fuel \\
\hline$R_{0}$ & universal gas constant & $g$ & gas \\
\hline$T$ & temperature & $O$ & oxidizer \\
\hline$t$ & time & $s$ & solid \\
\hline$u$ & $x$-direction velocity & $v$ & vapor \\
\hline$v$ & $y$-direction velocity & $w$ & water \\
\hline
\end{tabular}

\section{INTRODUCTION}

Water mist fire protection has been an object of intensive investigation and discussions over last years [1-3]. The primary properties that make water mist a highly effective flame suppression agent are high rates of heat and radiation absorption.

Traditionally, water mist is considered as a volume flooding agent, which act similarly to gaseous suppressants. In order for water mist to suppress fire in such a way, it has to be distributed fairly uniformly within the compartment. This task faces technological difficulties due to very small size of water droplets comprising mist. For example, momentum of strong fire plume is hard to overcome for water mist spray. Such difficulties force application of multiple mist nozzles which significantly increase cost of protection systems and amount of discharged water [4].

In the present paper, the authors assess potential of the "spot" or "local" application of water mist. This potential has not yet been neither fully appreciated, nor properly researched. One of important development in that direction is suppression of local flame spread. It is well known that flame spread is a primary fire growth mechanism, leading to uncontrollable combustion and eventually to flashover. Ability to be able to suppress (or restrict) flame spread at early stages is therefore, extremely important. Another important rationale for this approach is the fact that it is small-scale fires that are most difficult to extinguish by "total flooding" application [4].

The present paper focuses on the mechanism of flame suppression at its leading edge. Leading edge can be considered as a "weak" point of flame, where delicate heat transfer rate balance ensures flame propagation. It is envisaged that such a balance can be destroyed by water mist without much difficulty. The present study focuses on horizontal flame spread, where the flame leading edge is explicitly exposed to mist.

It should be noted that the concept of local mist application could be significantly extended and include downward or upward flame spread suppression, flammable ceiling protection against ceiling jets, heat extraction by water mist from smoke layer, and other strategies. Some initial work in this direction has already been done $[5,6]$.

On the other hand, further progress in the mathematical modeling of compartment fires by the approach of Computational Fluid Dynamics [7] requires detailed arrangement of submodels, which describe the number of physical, chemical, mechanical and other possible processes involved into fire development. Among them, flame spread process, being an actual driving force of fire, is to be considered as the key one, and achievement of proper knowledge of its basic behavior is of great interest (see e.g., [8-12]). Aimed at the development of advanced CFD code for fire modeling, investigation of the fire suppression mechanisms is the topic of high importance. 
Difficulties associated with the suppression modeling have well being realized [5-7]. Despite good recent progress in CFD modeling of water mist suppression [13,14], many important issues remain unresolved.

\section{MATHEMATICAL MODEL}

A set of governing equations represents the coupled analysis of the flame spread problem, which reflects the very essential phenomenon of self-controlling mechanism of interaction between the gas-phase combustion and pyrolysis reactions. Unsteady, twodimensional conservation equations are solved both in the gas phase and solid fuel. Since small-scale flame is considered, laminar flow and negligible radiation are assumed. Gasphase conservation equations are as follows:

$$
\begin{aligned}
& \rho \frac{\partial u}{\partial t}+\rho u \frac{\partial u}{\partial x}+\rho v \frac{\partial u}{\partial y}=\frac{\partial}{\partial x} \mu \frac{\partial u}{\partial x}+\frac{\partial}{\partial y} \mu \frac{\partial u}{\partial y}-\frac{\partial p}{\partial x}, \\
& \rho \frac{\partial v}{\partial t}+\rho u \frac{\partial v}{\partial x}+\rho v \frac{\partial v}{\partial y}=\frac{\partial}{\partial x} \mu \frac{\partial v}{\partial x}+\frac{\partial}{\partial y} \mu \frac{\partial v}{\partial y}-\frac{\partial p}{\partial y}+\left(\rho_{a}-\rho\right) g, \\
& \frac{\partial \rho}{\partial t}+\frac{\partial \rho u}{\partial x}+\frac{\partial \rho v}{\partial y}=0, \\
& C \rho \frac{\partial T}{\partial t}+C \rho u \frac{\partial T}{\partial x}+C \rho v \frac{\partial T}{\partial y}=\frac{\partial}{\partial x} \lambda \frac{\partial T}{\partial x}+\frac{\partial}{\partial y} \lambda \frac{\partial T}{\partial y}-L_{v} m_{w}+Q \rho W, \\
& \rho \frac{\partial Y_{O}}{\partial t}+\rho u \frac{\partial Y_{O}}{\partial x}+\rho v \frac{\partial Y_{O}}{\partial y}=\frac{\partial}{\partial x} \rho D \frac{\partial Y_{O}}{\partial x}+\frac{\partial}{\partial y} \rho D \frac{\partial Y_{O}}{\partial y}-v_{O} \rho W, \\
& \rho \frac{\partial Y_{F}}{\partial t}+\rho u \frac{\partial Y_{F}}{\partial x}+\rho v \frac{\partial Y_{F}}{\partial y}=\frac{\partial}{\partial x} \rho D \frac{\partial Y_{F}}{\partial x}+\frac{\partial}{\partial y} \rho D \frac{\partial Y_{F}}{\partial y}-v_{F} \rho W, \\
& \rho \frac{\partial Y_{v}}{\partial t}+\rho u \frac{\partial Y_{v}}{\partial x}+\rho v \frac{\partial Y_{v}}{\partial y}=\frac{\partial}{\partial x} \rho D \frac{\partial Y_{v}}{\partial x}+\frac{\partial}{\partial y} \rho D \frac{\partial Y_{v}}{\partial y}+m_{w} . \\
& \partial u \frac{\partial Y_{w}}{\partial x}+\rho v \frac{\partial Y_{w}}{\partial y}=-m_{w},
\end{aligned}
$$


Equation 7 for water mist mass fraction has been added to the basic flame spread statement represented by Eqs. 1-6, which includes corresponding term describing energy consumption due to water evaporation. Fine water mist (droplet diameters under 100 microns) is considered and, at least at present stage, droplet velocities are assumed equal to those of gas flow. Density, thermal conductivity and specific heat of the twophase mixture are related to the corresponding properties of the phases as follows:

$$
\begin{aligned}
& \rho=\frac{\rho_{g} \rho_{w}}{\rho_{g} Y_{w}+\rho_{w}\left(1-Y_{w}\right)}=\frac{p \rho_{w}}{p Y_{w}+R T \rho_{w}\left(1-Y_{w}\right)}, \\
& \lambda=\lambda_{w} Y_{w}+\lambda_{g}\left(1-Y_{w}\right), \\
& C=C_{w} Y_{w}+C_{g}\left(1-Y_{w}\right) .
\end{aligned}
$$

Here the gas density is calculated from the ideal gas state law:

$\rho_{g}=\frac{p}{R T}$

It is necessary to adjust the component concentrations (Eqs. 5-7) due to presence of water vapor, which mass fraction $Y_{v}$ is obtained through Eq. 8:

$\tilde{Y}_{i}=\frac{Y_{i}}{1+Y_{v}}, i=\{O, F, v\}$

The rate of water vaporization is as follows:

$m_{w}=-\frac{d m_{w}}{d t}=-N \frac{d m_{w}^{*}}{d t}$.

where $m_{w}=\rho Y_{w}$ is mass of all droplets in the unit volume; $m_{w}^{*}=\frac{\rho_{w} \pi D_{w}^{3}}{6}$ is mass of one droplet of the diameter $D_{w}$, and $N=\frac{m_{w}}{m_{w}^{*}}=\frac{6 \rho Y_{w}}{\rho_{w} \pi D_{w}^{3}}$ is number of droplets in the unit volume. It is assumed that droplets have the same local temperature and velocity as the gas until they reach evaporation temperature. Relevant justification can be made upon comparing droplet thermal and drag constants with their residence time in the flame front. Residence time is estimated as $\chi / V^{2}$ where $\chi=\lambda / \rho_{g} C$ is the gas thermal diffusivity and $V$ is the gas velocity in flame. The droplet thermal constant can be estimated as 
$\frac{\rho_{w} C\left(D_{w}^{2} / 6\right)}{\lambda N u}$

where $\mathrm{Nu}$ is Nusselt number applicable to droplet moving in the gas. It can be shown that Stoke's regime assumption is appropriate for droplet movement. The drag time constant estimation following from this law is $\frac{\rho_{w}}{\rho_{g}} \frac{D_{w}^{2}}{(32 v)}$ which involves ratio of phase densities and gas kinematic viscosity $v=\mu / \rho_{g}$. Upon introduction of these characteristic time scales, it is apparent (for droplets diameter of the order of $\sim 30 \mu \mathrm{m}$ considered in the paper) that the ratio between droplet thermal constant and residence time is $\sim 10^{-5}$; the ratio between droplet drag time constant and residence time is $\sim 10^{-6}$. Therefore, both assumptions of instantaneous relaxation of droplet temperatures and velocities to those of gas are perfectly justified.

It can be assumed with a good accuracy that the droplet vaporization follows the wellknown " $D^{2}$-law" [15]:

$\frac{d D_{w}^{2}}{d t}=\left\{\begin{array}{c}-k_{w}, \quad T \geq T_{v} \\ 0, \quad T<T_{v}\end{array}\right.$.

where $T_{v}$ is water vaporization temperature, $k_{w}$ is evaporation constant. This expression is universally applicable after the droplet heat-up period. Evaporation during the droplet heat-up period is neglected in the present study. Thus for $T \geq T_{v}$ $\frac{d m_{w}^{*}}{d t}=\frac{\rho_{w} \pi}{6} \frac{d D_{w}^{3}}{d t}=-\frac{\rho_{w} \pi}{4} D_{w} k_{w}$, and finally, water evaporation rate is expressed as

$m_{w}=\left\{\begin{array}{l}\frac{3}{2} \frac{\rho Y_{w}}{D_{w}^{2}} k_{w}, \quad T \geq T_{v} . \\ 0, \quad T<T_{v}\end{array}\right.$.

The energy equation for the solid fuel is

$C_{s} \rho_{s} \frac{\partial T_{s}}{\partial t}=\frac{\partial}{\partial x} \lambda_{s} \frac{\partial T_{s}}{\partial x}+\frac{\partial}{\partial y} \lambda_{s} \frac{\partial T_{s}}{\partial y}+Q_{s} \rho_{s} W_{s}$.

Present analysis is focused on the suppression of the flame leading edge, which implies that finite-rate chemical reactions are taken into account for the gas phase combustion and solid fuel's pyrolysis in the conventional Arrhenius form:

$W=k Y_{O} Y_{F} \exp \left(-E / R_{0} T\right)$

$W_{S}=k_{S} \exp \left(-E_{S} / R_{0} T_{S}\right)$ 
The simple one-step global expression is considered here in the view of general study which is primarily focused on thermal effects of flame spreading and suppression. More realistic kinetics can be easily introduced into the model to address specific flame structure in more detail.

Linear pyrolysis rate at the solid fuel's surface is expressed as [9]:

$$
v_{S}(x, t)=\int_{-\delta(x, t)}^{0} W_{s} d y
$$

Initial and boundary conditions for the mathematical statement presented here are of commonly used form [9,16] and solution procedure [9] is based on the combined algorithm using the finite difference (control volume) approach for the gas phase and finite element one for the solid material.

Mist deposition on the surface and its subsequent effect on the flame spread is not modeled in the present study. It is assumed that extinction (if any) occurs shortly after injection of the mist. Therefore, wetting of the surface is negligible.

\section{RESULTS AND DISCUSSION}

Numerical investigations of the horizontal flame spread over polymeric material (PMMA) under water mist suppression have been carried out. Thick layer of fuels has been considered to avoid material depletion. Thermophysical and kinetic characteristics used in the calculations are presented in Table 1. Other necessary constants relate to the modeling of water droplet evaporation: $\rho_{w}=1000 \mathrm{~kg} / \mathrm{m}^{3}, \lambda_{w}=0.56 \mathrm{~W} /(\mathrm{m} \mathrm{K}), C_{w}=4186$ $\mathrm{J} /(\mathrm{kg} \mathrm{K}), L_{V}=2.26 \cdot 10^{6} \mathrm{~J} / \mathrm{kg}, k_{w}=1.47 \cdot 10^{-7} \mathrm{~m}^{2} / \mathrm{s}, T_{V}=373 \mathrm{~K}$.

Table 1. Gas phase and solid fuel properties.

\begin{tabular}{|c|c|c|c|}
\hline Symbol & Gas & Solid & Unit \\
\hline$C$ & 1005.6 & 1466.5 & $\mathrm{~J} /(\mathrm{kg} \mathrm{K})$ \\
\hline$\lambda$ & 0.0254 & 0.19 & $\mathrm{~W} /(\mathrm{m} \mathrm{K})$ \\
\hline$\rho$ & $1.29^{\mathrm{a}}$ & 1200 & $\mathrm{~kg} / \mathrm{m}^{3}$ \\
\hline$p$ & $10^{5}$ & - & $\mathrm{Pa}$ \\
\hline$Q$ & $2.5 \cdot 10^{7}$ & $-1.0 \cdot 10^{6}$ & $\mathrm{~J} / \mathrm{kg}$ \\
\hline$k$ & $1.0 \cdot 10^{16}$ & $2.82 \cdot 10^{9}$ & $1 / \mathrm{s}$ \\
\hline$E$ & 62850 & 129890 & $\mathrm{~J} / \mathrm{mol}$ \\
\hline$v_{F}$ & 1.0 & - & - \\
\hline$v_{O}$ & 1.9 & - & - \\
\hline$T_{a}$ & 300 & 300 & $\mathrm{~K}$ \\
\hline$L_{0}$ & - & 3.0 & $\mathrm{~mm}$ \\
\hline
\end{tabular}
at the ambient temperature.

First, calculations of the flame spread in normal conditions (without the presence of water mist) have been carried out from the ignition until the sustainable propagation process. Achieved values of flame propagation velocities $\left(u_{f}=3.49 \cdot 10^{-5} \mathrm{~m} / \mathrm{s}\right.$ for $Y_{O, a}=0.21$ and 
$u_{f}=1.42 \cdot 10^{-4} \mathrm{~m} / \mathrm{s}$ for $Y_{O, a}=0.33$ ) are in reasonable agreement with known experimental and theoretical data $[12,17,18]$.

Then, flame is exposed to the water mist generator located at some distance in front of the flame leading edge. Typical distributions of temperature and water mist mass fraction are shown in Figs. 1 and 2 respectively. Here suppression starts at $t=0$, which corresponds to normal flame spread. The water droplets are discharged to the flame edge by the flow formed by buoyancy effect in the heat release zone. Typical distribution of the flow field is shown in Fig. 3. The shape of isolines of equal droplet concentrations in Fig. 2 is a combination of convective and vaporization effects. As droplets are drawn into the flame, the concentration drops, and the isolines separate from each other. Upstream, in front of the leading edge, the isolines asymptotically approach each other, and at the same time approach ambient (uniform) droplet concentration.
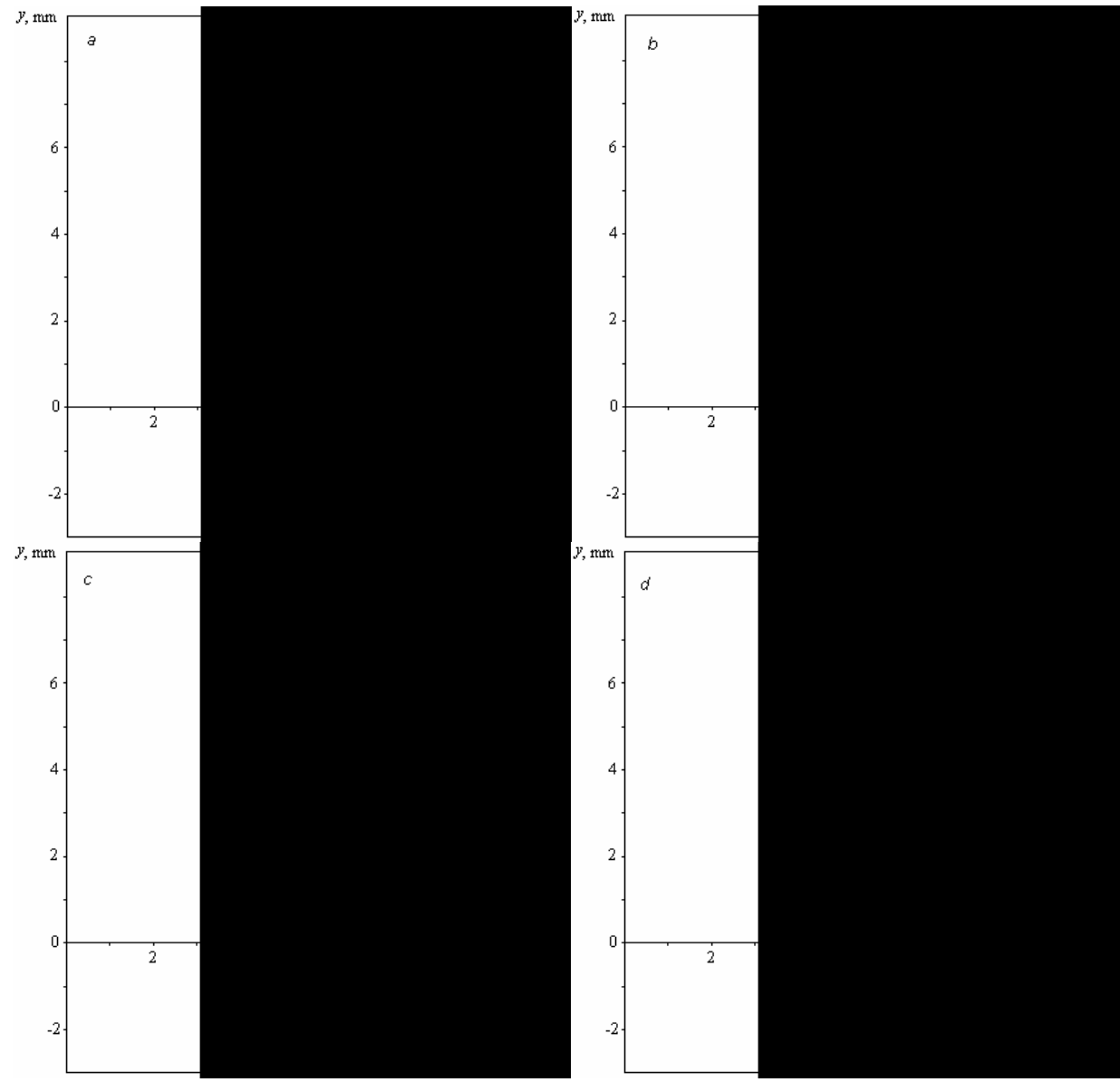

Fig. 1. Temperature isolines (K) in the flame zone; $Y_{O, a}=0.33, Y_{w, a}=0.01$, $D_{w}=30 \mu \mathrm{m} ; a-t=0, b-t=0.4 \mathrm{~s}, c-t=0.6 \mathrm{~s}, d-t=0.75 \mathrm{~s}$. 

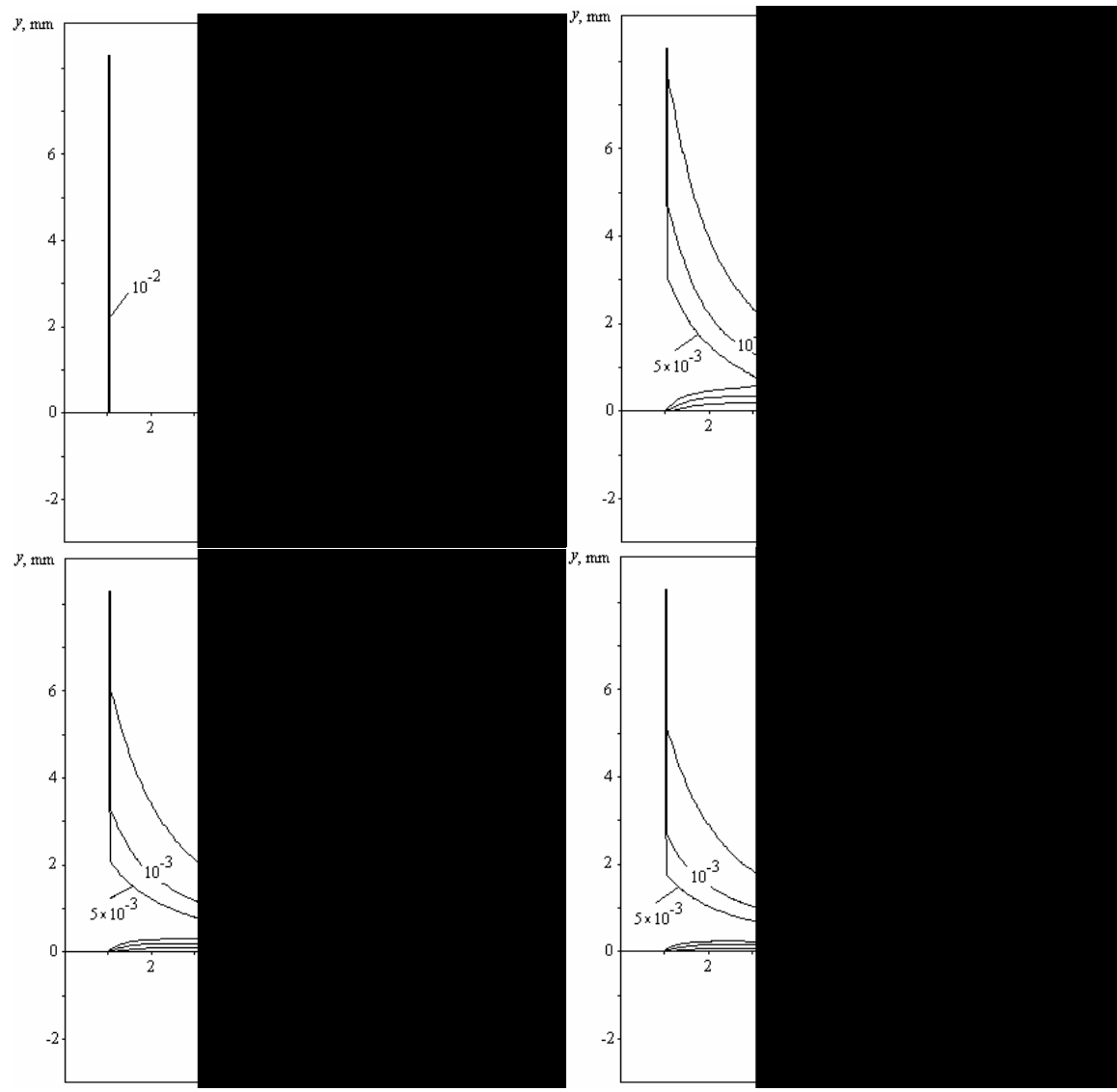

Fig. 2. Water mist concentration isolines in the flame zone; $Y_{O, a}=0.33, Y_{w, a}=0.01$, $D_{w}=30 \mu \mathrm{m} ; a-t=0, b-t=0.4 \mathrm{~s}, c-t=0.6 \mathrm{~s}, d-t=0.75 \mathrm{~s}$.

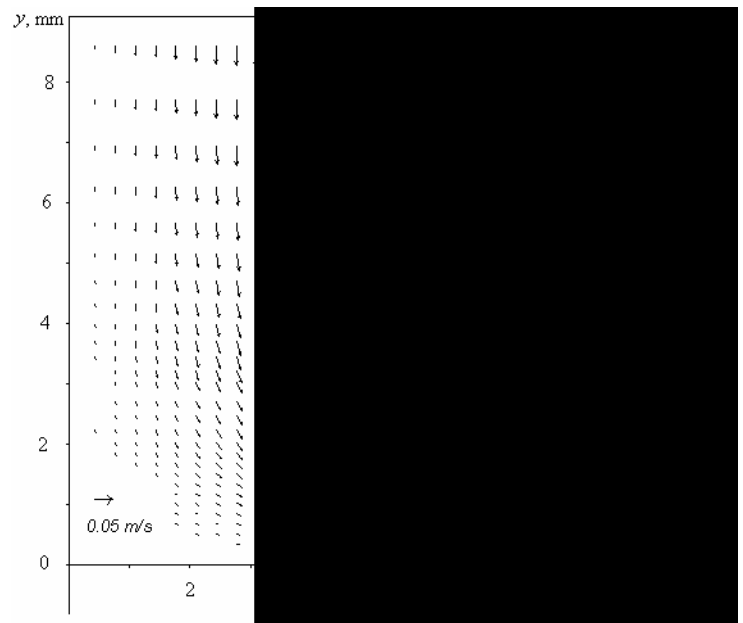

Fig. 3. Flow field in the flame zone. 
It has to be noted that the same behavior of flame spread extinction (if it actually occurs) has been observed for all investigated cases. Intensive cooling of the flame heat release zone by the water droplets evaporation results the appearance of negative values of the heat flux on the fuel's surface as shown by the curves 3 and 4 of Fig. 4 .

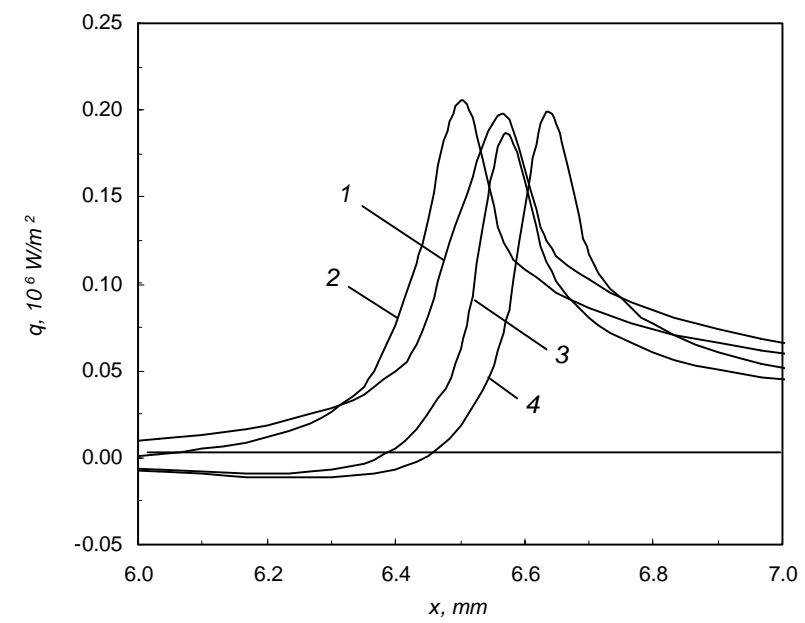

Fig. 4. Distribution of the heat flux on the solid fuel's surface; $Y_{O, a}=0.33$,

$$
Y_{w, a}=0.01, ; 1-t=0,2-t=0.4 \mathrm{~s}, 3-t=0.6 \mathrm{~s}, 4-t=0.75 \mathrm{~s} \text {. }
$$

Figure 5 presents the essence of flame extinguishment behavior for different input water mist mass fractions. As water mist approaches flame edge (approximately within $0.4 \mathrm{~s}$ ), the movement direction of the point of maximal heat flux on the fuel's surface shown in Fig. 4., reflects the effect of interaction between flame and water mist. The overall results have shown that self-sustained energy balance in the heat release zone in the flame is highly sensitive to the external energy loss, which in this case is due to water droplet evaporation. This results in the fact that flame struggles against the presence of water mist on the flame leading edge and either continues to propagate with almost the same velocity (as of without water mist), or complete extinction occurs.

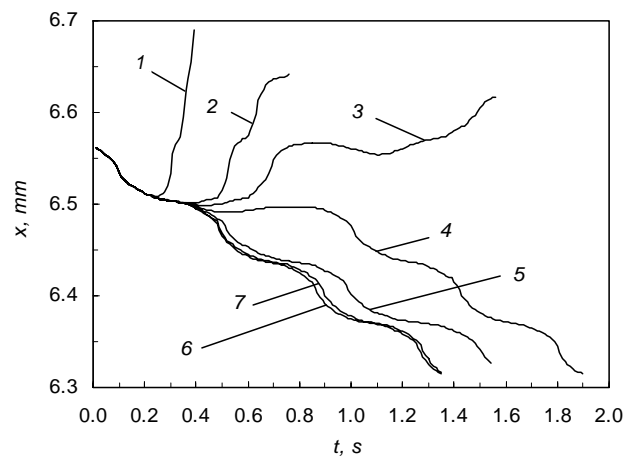

Fig. 5. Movement of the point of maximal heat flux on the fuel's surface; $Y_{O, a}=0.33$;

$$
\begin{gathered}
1-Y_{w, a}=0.1,2-Y_{w, a}=0.01,3-Y_{w, a}=0.005,4-Y_{w, a}=0.0025, \\
5-Y_{w, a}=0.001,6-Y_{w, a}=0,7-Y_{w, a}=0.1\left(L_{v}=0\right) .
\end{gathered}
$$


The value of flame propagation velocity could be estimated by the averaged slopes of the descending parts of the curves 4-7 shown in Fig. 5. Some difference in these slopes corresponds to the region where flame is able to spread with the slightly lower velocity (in comparison to normal condition). This region is apparently very narrow, which clearly reveals the critical value of water mist characteristics providing flame extinction. Flame spread rates estimated from curves 1-3 up to the point of these curves reversal (extinction) are consistent with the spread rates estimated from the curves 4-7.

It is believed that the mechanism of extinction is reduction in thermal heat flux to the surface of material, leading to insufficient pyrolysis rate in front of the leading edge of the flame.

Remarkable fact has been shown by the curve 7 of Fig. 5, which corresponds to the treatment of water mist as a purely flooding agent. It can be noted that there is no flame extinguishment effect even for the rather high input water mist concentration.

The same behavior has been achieved for the flame spread in air $\left(Y_{O, a}=0.21\right)$, which is shown in Fig. 6. It has to be noted that in this case, flame already propagates near the extinction limit [19] and water mist affects the flame propagation more intensively as flame life-time in the presence of water droplets decreases from $0.4 \mathrm{~s}$ to $0.2 \mathrm{~s}$.

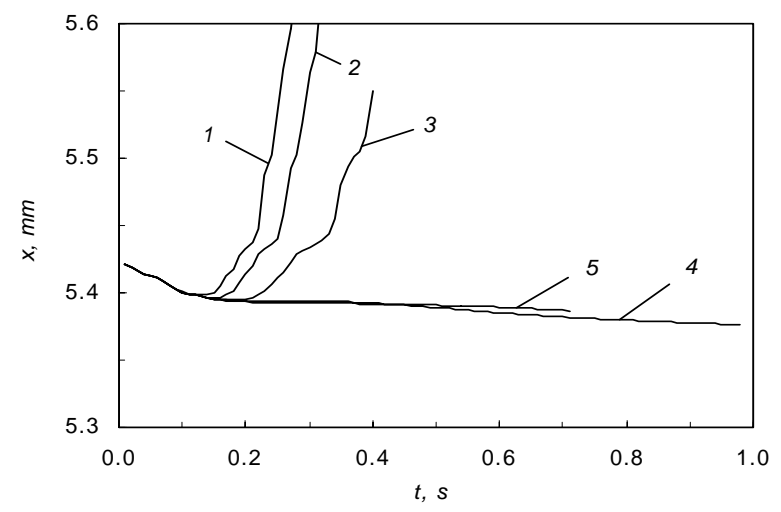

Fig. 6. Movement of the point of maximal heat flux on the fuel's surface;

$$
\begin{gathered}
Y_{O, a}=0.21 ; 1-Y_{w, a}=0.1,2-Y_{w, a}=0.05,3-Y_{w, a}=0.01, \\
4-Y_{w, a}=0,5-Y_{w, a}=0.1\left(L_{v}=0\right) .
\end{gathered}
$$

\section{CONCLUDING REMARKS}

Mathematical model has been presented to describe flame spread suppression by localized application of fine water mist. Simulations of laminar flame spread over horizontal PMMA sample have been carried out. The critical concentration required for suppression has been established for representative droplet size. Generally, achieved results showed a reasonable behavior of investigated process as being addressed to the experimental study of similar process [20].

A very important conclusion of the present study is that mist does not affect the rate of flame spread. The flame either propagates at the same velocity as of without water mist, or extinction occurs at critical water mist concentration. 


\section{REFERENCES}

[1] Science, Technology and Standards for Fire Suppression System -- Proceedings of the Second NRIFD Symposium, National Research Institute of Fire and Disaster, Tokyo, 2002.

[2] Proceedings of the International Water Mist Conference, International Water Mist Association, Vienna, 2001.

[3] Grant, G., Brenton, J., and Drysdale, D., "Fire Suppression by Water Sprays," Progress in Energy and Combustion Science, 26, (2): 79-130, (2000).

[4] Wighus, R., "Water Mist Fire Suppression Technology - Status and Gaps in Knowledge," Proceedings of the International Water Mist Conference, International Water Mist Association, Vienna, 2001, pp. 1-26.

[5] Novozhilov, V., "Fundamentals and Application of Fire Suppression Modeling," Science, Technology and Standards for Fire Suppression Systems --Proceedings of the Second NRIFD Symposium, National Research of Fire and Disaster, Tokyo, 2002, pp. 195-215.

[6] Novozhilov, V., "Flashover Control Under Fire Suppression Conditions," Fire Safety Journal, 36, (7): 641-660, (2001).

[7] Novozhilov, V., "Computational Fluid Dynamics Modeling of Compartment Fires,” Progress in Energy and Combustion Science, 27: 611-666, (2001).

[8] Di Blasi, C., "Modeling and Simulation of Combustion Processes of Charring and Non-charring Solid Fuels,” Progress in Energy and Combustion Science, 19, (1): 71-104, (1993).

[9] Karpov, A.I., Galat, A.A., and Bulgakov, V.K., "Prediction of the Steady Flame Spread Rate by the Principle of Minimal Entropy Production,” Combustion Theory and Modelling, 3: 535-546, (1999).

[10] Bhattacharjee, S., King, M.D., and Paolini, C., "Structure of Downward Spreading Flames: a Comparison of Numerical Simulation, Experimental Results and a Simplified Parabolic Theory," Combustion Theory and Modelling, 8: 23-39, (2004).

[11] Kumar, A., Shih, H.Y., and T'ien, J.S., "A Comparison of Extinction Limits and Spreading Rates in Opposed and Concurrent Spreading Flames over Thin Solids," Combustion and Flame, 132: 667-677, (2003).

[12] Wu, K.K., Fan, W.F., Chen, C.H., Liou, T.M., and Pan, I.J., "Downward Flame Spread over a thick PMMA slab in an Opposed Flow Environment: Experiment and Modeling," Combustion and Flame, 132: 697-707, (2003).

[13] Prasad, K., Li, C., and Kailasanath, K., "Simulation of Water-Mist Suppression of Small Scale Methanol Liquid Pool Fires,” Fire Safety Journal, 33: 185-212, (1999).

[14] Prasad, K., Patnaik, G., and Kailasanath, K., "A Numerical Study of Water-Mist Suppression of Large Scale Compartment Fires," Fire Safety Journal, 37: 569589, (2002).

[15] Lefebvre, A.H., “Atomization and Sprays,” Hemisphere, New York, 1989. 
[16] Karpov, A.I., Bulgakov, V.K., Galat, A.A., and Novozhilov, V., "Numerical Modeling of Water Mist Suppression of Small Scale Flame Spreading over Solid Combustibles," Proceedings of the Sixth Asia-Oceania Symposium on Fire Science and Technology, Daegu, Korea, 2004, pp. 922-934.

[17] Tewarson, A., and Ogden, S.D., "Fire Behavior of Polymethylmethacrylate," Combustion and Flame, 89: 237-259, (1992).

[18] Fernandez-Pello, A.C., Ray, S.R., and Glassman, I., "Flame Spread in an Opposed Forced Flow: the Effect of Ambient Oxygen Concentration," Proceedings of Eighteen International Symposium on Combustion, Combustion Institute, 1981, pp.579-589.

[19] Frey, A.E., and T'ien, J.S., "Near-limit Flame Spread over Paper Samples," Combustion and Flame, 26: 257-267, (1976).

[20] Tsuruda, T., Liao, C., and Saito, N, "Observation of Extinction of a PMMA Cylinder Flame with a Fine Water Mist," Proceedings of the Fifth Asia-Oceania Symposium on Fire Science and Technology, Newcastle, Australia, 2001. 